\title{
Coal combustion modelling in a frontal pulverized coal-fired boiler
}

\author{
Pawet Madejski ${ }^{1, *}$ \\ ${ }^{1}$ AGH University of Science and Technology, Faculty of Mechanical Engineering, Department of \\ Power Systems and Environmental Protection Facilities, Mickiewicza 30 Av. 30-059 Kraków, Poland
}

\begin{abstract}
The paper presents results of numerical modelling of pulverized coal combustion process in the coal-fired boiler. In the numerical model, coal combustion process includes particle heating, devolatilization, char combustion, as well as turbulent flow and radiative heat transfer was modelled. Presented modelling results were carried out using the Open Source CFD code - Code_Saturne created and developed by EDF R\&D and were used to study the combustion of coal in power plant boiler with the objective of simulating the operational conditions and identifying factors of inefficiency. The behaviour of the flow of air and pulverized coal through the burners was modelled, and the three-dimensional flue gas flow through the combustion chamber and heat exchangers was reproduced in the simulation.
\end{abstract}

\section{Introduction}

Currently, the coal fired power plants are facing new big challenge resulting from environmental concerns. The units must meet strict limits for emissions of gaseous pollutants keeping efficiency on the high level. Applying methods for reducing pollutant emission in the wrong way can greatly affect the process quality and reduce production efficiency.

The development of computer modelling techniques, especially the CFD methods (Computational Fluid Dynamics) allows to conduct the accurate analysis of coal combustion process and are widely used in modelling of front-fired boilers [1-2] as well as tangentially-fired boilers [3-5]. A complete information about the combustion process resulting from CFD model is helpful in the verification of combustion process quality. The analysis results of combustion process using CFD modelling can be used in optimization processes eg. to proper prediction of NOx reduction using primary or secondary methods $[6,7]$, to verify actual operating conditions and them impact on the thermo-flow processes inside the coal boilers [8-10], as well as to analyse different types of fuels as biomass, waste etc. [11-13].

\footnotetext{
* Corresponding author: madejski@agh.edu.pl
} 


\section{Characteristic of front-fired pulverized coal boiler}

The numerical simulation was performed for the front-fired pulverized coal boiler, with a natural circulation. The nominal temperature of live and reheated steam produced in the boiler is equal to $540^{\circ} \mathrm{C}$ at the pressure equal to $13.5 \mathrm{MPa}$ and $2.5 \mathrm{MPa}$ of live and reheated steam respectively. The fuel is a hard coal with an average calorific value around of $20.500 \mathrm{MJ} / \mathrm{kg}$.

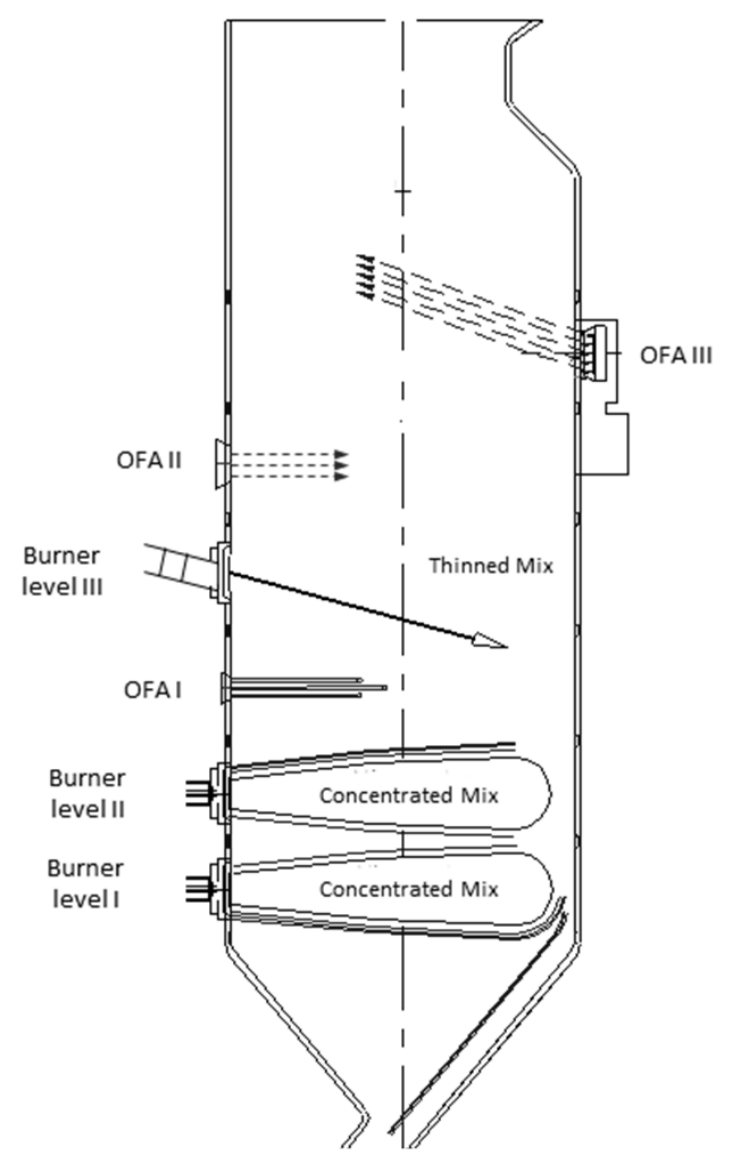

Fig. 1. Firing system of a frontal pulverized coal-fired boiler

The general scheme of analysed boiler with low-NOx furnace system is depicted in Figure 1. The low-NOx combustion system is characterized by air and fuel staging. The pulverized coal supplies boiler by 12 swirl low-NOx burners (burner level I and II) divided into two rows and by 12 burners (burner level III) located in the upper part of windbox (Figure 1). This system consists also of two levels of Over Fired Air nozzles (OFA) located at the front wall (6 OFA ports) and rear boiler wall (10 OFA ports). Boiler has an additional air inlets in order to avoid low-oxygen corrosion processes (protective air) and to decrease UBC content (bottom air). The share of protective and bottom air in total amount of air supplied to the boiler can be up to $20 \%$ and has to be taken into account in simulations. The number and location of all boiler inlets are presented in Table 1. 
Table 1. Total number of all inlets in the boiler

\begin{tabular}{|c|c|c|}
\hline Inlet & Side & Inlet numbers \\
\hline Low-NOx burner & Front & $2 \times 6$ \\
\hline Burner & Front & 12 \\
\hline OFA & Front & 6 \\
\hline OFA & Rear & 10 \\
\hline Bottom air & Bottom & 20 \\
\hline Protective air & Rear & 15 \\
\hline Protective air & Left & 5 \\
\hline Protective air & Right & 5 \\
\hline
\end{tabular}

To perform simulation, the properties of coal were defined based on the results from proximate and elemental analysis. The characterization of bituminous coal burned in Power Plant is presented in Table 2.

Table 2. Results of proximate and elemental analtysis used in coal combustion modeling (AR - As Received)

\begin{tabular}{|c|c|}
\hline Proximate analysis & Value, wt\% (AR) \\
\hline Ash & 22.34 \\
\hline Volatile Matter & 25.77 \\
\hline Moisture & 12.75 \\
\hline Fixed Carbon & 39.14 \\
\hline Elemental analysis & Value, wt\% (AR) \\
\hline $\mathrm{C}$ & 84.7 \\
\hline $\mathrm{H}$ & 5.39 \\
\hline $\mathrm{O}$ & 1.55 \\
\hline $\mathrm{N}$ & 1.55 \\
\hline $\mathrm{S}$ & 1.23 \\
\hline
\end{tabular}

\section{Operating conditions}

The simulation was carried out for steady-state boiler operating and for the boiler load close to the nominal value. Operating conditions were determined based on the measured values registered by on-line measurement system (Table 3 ). 
Table 3. Furnace operating conditions used in simulation

\begin{tabular}{|c|c|c|}
\hline Name & Mass flow rate, $\mathbf{k g} / \mathbf{s}$ & Temperature, $\mathbf{K}$ \\
\hline Coal & 24.18 & 386 \\
\hline Primary air & 75.73 & 386 \\
\hline Secondary air & 89.9 & 573 \\
\hline Protective air + bottom air & 40.41 & 573 \\
\hline
\end{tabular}

The share of coal and air for the individual inlets was determined based on the knowledge and experience from previous numerical studies and on-site tests. The particle size distribution was calculated based on the sieve analysis results. The percent of particles passing through two different sieves were measured for each coal mill. The average values for all 6 pulverized coal mills $\left(\mathrm{R}_{88}=11.5 \%, \mathrm{R}_{200}=0.7 \%\right)$ and Rosin-Rammler law were used to calculate coal particle distribution:

$$
P\left(d_{i}\right)=1-\exp \left(-d_{i} / D_{m}\right)^{n}
$$

mwhere :

$n \quad-\quad$ factor of spread in particle sizes,

$d_{i} \quad-\quad$ coal particle diameter of class i, m,

$D_{m} \quad-\quad \mathrm{t}$ mean coal particle diameter, $\mathrm{m}$.

Five classes of particle diameter $\left(d_{1}=4.9 \mu \mathrm{m}, d_{2}=16.9 \mu \mathrm{m}, d_{3}=43.7 \mu \mathrm{m}, d_{4}=90 \mu \mathrm{m}, d_{5}=150\right.$ $\mu \mathrm{m})$ were used for burners on Level I and II (concentrated coal-air mixture) and for burners on Level III (thinned coal-air mixture).

\section{Modelling of pulverized coal-fired boiler operation}

The simulation of pulverized coal combustion in a power plant boiler was performed in the Open Source CFD code - Code_Saturne, created and developed by EDF R\&D [14,15]. The calculations were conducted for steady-state conditions and for boundary conditions prepared based on the available technical documentation of a boiler and measured values of boiler operating conditions.

To conduct calculations of the pulverized-coal fired boiler, the following processes as coal combustion including a devolatilization process, char and gas phase combustion as well as turbulent flow and radiative heat transfer need to be modelled. In the developed model presented in the paper, the mixture fraction approach together with using of Probability Density Function (PDF function) was adopted. Turbulent flow was modelled using standard k- $\varepsilon$ model and to calculate radiative heat transfer the Discrete Ordinate model with 32 directions of heat transfer has been applied.

\subsection{Geometrical model and numerical mesh}

This three dimensional geometrical model of front-fired pulverized coal boiler analysed in the paper was created based on the technical documentations. Figure 2 shows the model of two passes boiler including low-emission firing system with main swirl burners and burners in form of drop tubes, water-walls, protective air nozzles, bottom air and Over-Fire Air nozzles located on the front wall. Additionally at the outlet of a first boiler pass superheater consisting of plates distributed over the width of the whole boiler was created. 


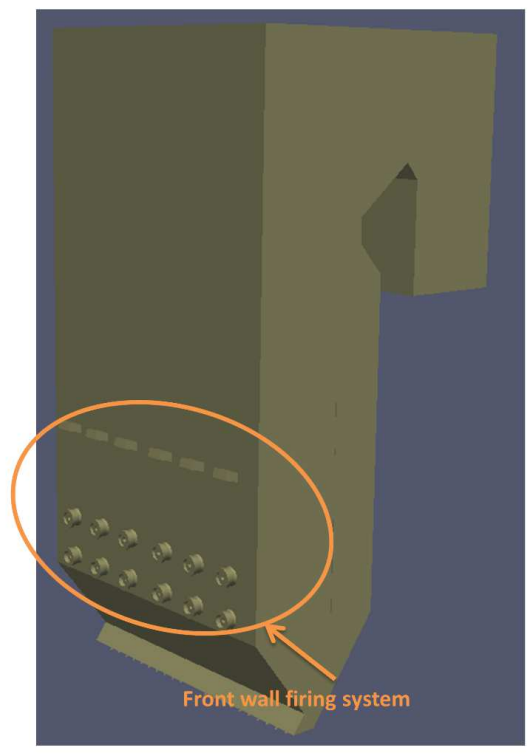

Fig. 2. Three dimensional geometric model of boiler

Numerical mesh consisted of about 3 million control volumes, mainly made of hexahedral elements type, was used to conduct calculations. In order to ensure a proper distribution of pulverized coal and air, a dedicated numerical mesh of burners located on the front boiler wall was created.

\subsection{Coal combustion modelling}

To conduct calculations of pulverized coal combustion and furnace operation, the following processes need to be modeled: turbulent flow, radiative heat transport, coal combustion and gas phase combustion. The pulverized coal combustion process can be divided into devolatilization and char combustion and gas-phase combustion process. The devolatilization process is described by two-reaction rates model (Kobayashi model) with calculated yield values of light and heavy volatiles $Y_{1}$ and $Y_{2}$ [15]. The gas phase combustion process was simulated using mixture fraction/PDF model $[15,16]$. To simulate reactions of gas phase combustion, the transport equation for mixture fraction variable $f$ is solved. Based on the calculated local value of $f$ and using PDF Beta function [16,17], the mass fraction of fuel, product and oxidizer can be calculated.

\subsection{Boundary conditions}

The boundary conditions used in the developed boiler model have been defined on the basis of the measured values when the boiler was operating at constant load. The simulation also includes non-uniform fuel and air boiler distribution define as the different values of the mass flow rate at individual boiler inlets. Mass fractions of pulverized coal with different particle diameter was calculated using results from sieve analysis and RosinRammler distribution represented by Eq. (1). The boundary conditions at boiler water-walls 
and superheater walls were determined using balance calculations of boiler operation, and the temperature at the walls together with emissivity factors are presented in Table 4.

Table 4. Boundary conditions at the boiler walls

\begin{tabular}{|c|c|c|}
\hline Boundary surface & Temperature, ${ }^{\circ} \mathbf{C}$ & Emissivity \\
\hline Evaporator wall & 390 & 0.7 \\
\hline Burners wall & 730 & 1.0 \\
\hline Superheaters wall & 577 & 0.4 \\
\hline
\end{tabular}

\section{Results of boiler operation modelling}

The simulation of boiler operation was performed for steady state conditions and for input data defined and presented in previous sections. Carrying out the calculations of the boiler using a CFD modeling allows obtaining results in the form of distributions of key parameters such as velocity and gas temperature inside the boiler (Figure 4).

(a)

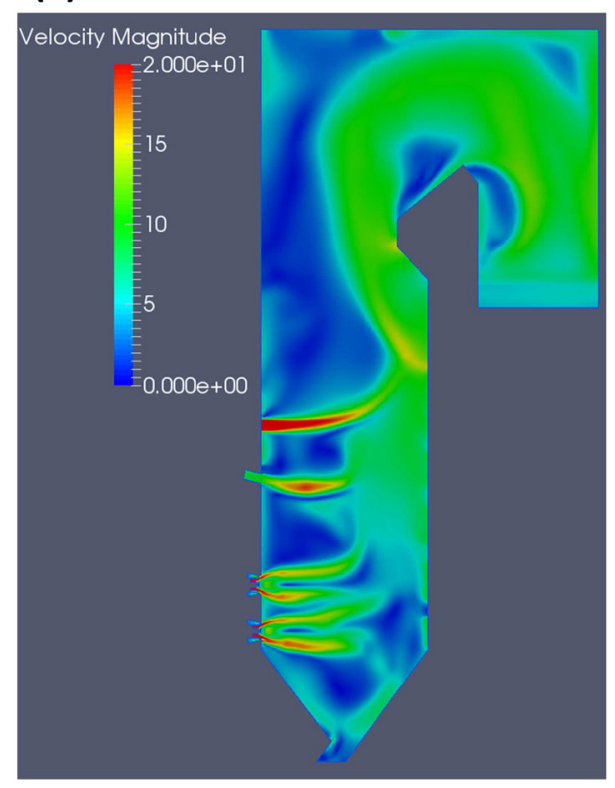

(b)

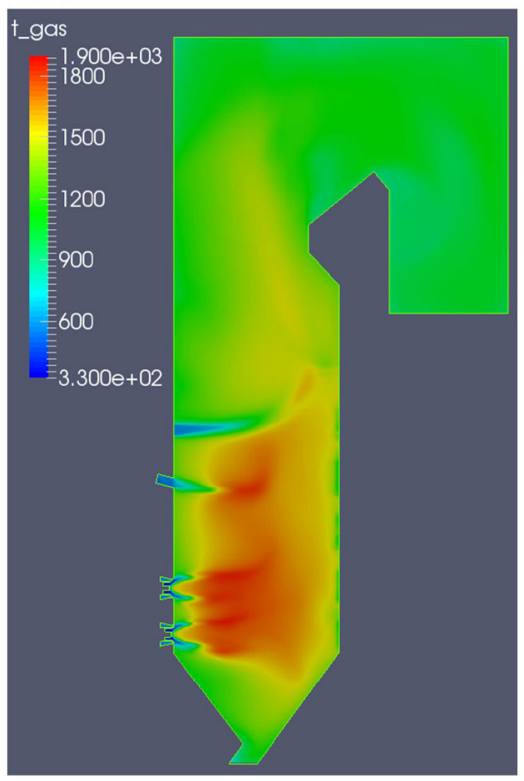

Fig. 3. Velocity (a) and gas temperature (b) distribution in a vertical plane of the boiler

Velocity distribution presented in Figure 4a allows identifying the exhaust gas flow path in the boiler and zones where the velocity reaches the highest values. The very high velocity of flue gases may be a danger of erosion hazard and can be the reason for too intensive convective heat transfer in local boiler zones. The temperature distribution inside the boiler is presented in Figure $4 \mathrm{~b}$, and allows identifying the zones where the greatest temperature exists. The highest temperatures occur in combustion zone, and also in the zone where the pulverized coal is supplied using drop tube burners. 


\section{Conclusions}

The paper presents results of numerical simulation of front-fired pulverized coal boiler operation carried out using Computational Fluid Dynamics modeling. The calculations were performed using Code Saturne code, which is the Open Source CFD software. In the developed model, the devolatilization process was described by two-reaction rates model (Kobayashi model) with calculated yield values of light and heavy volatiles. The gas phase combustion process was simulated using mixture fraction/PDF model. For turbulent flow modeling the standard k- $\varepsilon$ model was used and for radiative heat transfer, the Discrete Ordinate model with 32 directions of heat transfer has been applied. The results in form of velocity and temperature distribution can be used in order to answer some operational questions regarding optimization and combustion process efficiency inside large steam boilers. Thanks to the simulation results are possible to increase the understanding and detailed investigating of all processes inside the boiler and to determine and verify safe operating conditions.

This research was partially funded from GEKON program by the National Center of Research and Development and the National Fund for Environmental Protection and Water Management under research and development project No. GEKON1/O2/213655/9/2014. Author thanks for the support and the ability to carry out this work in collaboration with EDF R\&D, Fluid Dynamics Power Generation and Environment in Chatou France.

\section{References}

1. Minghou X., Azevedo J.L.T., Carvalho M.G., Modeling of a front wall fired utility boiler for different operating conditions, Comput Method Appl M, 190, pp. 3581-3590, (2001)

2. Sanghyun P., Jungeun A. K., Changkook R., Taeyoung Ch., Won Y., Young-Ju K., Ho-Young P., Hee-Chun L., Combustion and heat transfer characteristics of oxy-coal combustion in a 100 MWe front-wall-fired furnace, Fuel, 106, pp. 718-729, (2013)

3. Belosevic S., Sijercic M., Oka S., Tucakovic D., Three-dimensional modeling of utility boiler pulverized coal tangentially fired furnace, Int J Heat Mass Tran, 49, pp. 33713380, (2006)

4. Asotani T., Yamashita T., Tominga H., Uesugi Y., Itaya Y., Mori S., Prediction if ignition behavior in a tangentially fired pulverized coal boiler using CFD, Fuel, 87, pp. 482-490, (2008)

5. Fan J., Qian L., Ma Y., Sun P., Cen K., Computational modeling of pulverized coal combustion processes in tangentially fired furnaces, Chem Eng J. 81, pp. 261-269, (2001)

6. Dal Secco S., Juan O., Louis-Louisy M., Lucas Y-V., Plion P., Porcheron L., Using a genetic algorithm and CFD to identify low NOx configurations in an industrial boiler, Fuel, 158, pp. 672-683, (2015)

7. Modliński N., Numerical simulation of SNCR (selective non-catalytic reduction) process in coal fired grate boiler, Energy, 92, pp. 67-76, (2015)

8. Madejski P., Taler D., Analysis of temperature and stress distribution of superheater tubes after attemperation or sootblower activation. Energ Convers Manage, 71, pp. 131-137, (2013) 
9. Madejski P., Janda T., Taler J., Nabagło D., Węzik R., Mazur M., Analysis of fouling degree of individual heating surfaces in a pulverized coal fired boiler, J Energ ResourASME, 140, pp. 1-8, (2018)

10. Madejski P., Taler D., Taler J., Numerical model of a steam Superheater with a complex shape of the tube cross section using control volume based finite element method, Energ Convers Manage, 118, pp. 179-192, (2016)

11. Pająk T., Jurczyk M., Initial operating experience with the new Polish waste-to-energy plants, Waste Management, 6 Waste-to-energy, Eds: Karl J. Thomé-Kozmiensky, Stephanie Thiel (Neuruppin, TK Verlag Karl Thomé-Kozmiensky 2016)

12. Turlej T., Banaś M., Management of communal sewage waste in Poland, International Multidisciplinary Scientific GeoConference SGEM, 978, pp. 627-634, (2017)

13. Bhuiyan A.A., Naser J., CFD modelling of co-firing of biomass with coal under oxyfuel combustion in a large scale power plant, Fuel, 159, pp. 150-168, (2015)

14. Archambeau F., Mechitoua N., Sakiz M., Code_Saturne: A finite volume code for the computation of turbulent incompressible flows - industrial applications, IJFV International Journal On Finite Volumes, 1, pp. 1-64, (2004)

15. Code Saturne 3.3.0 Theory Guide, Fluid Dynamics, Power Generation and Environment Department, Single Phase Thermal-Hydraulics Group, EDF Lab Chatou, France May, (2014)

16. Pope S. B., The probability approach to the modelling of turbulent reacting flows, Combust Flame, 27, pp. 299-312, (1976)

17. Poinsot T., Veynante D., Theoretical and numerical combustion, second ed., (R.T. Edwards Inc., Philadelphia 2005) 